\title{
Mechanical Response of a Novel "Anti-slide Pile + Support Column" Composite Retaining Structure
}

\author{
Peng Duan ${ }^{1}$, Chunli Zhang ${ }^{1}$ and Mingzhen $\mathrm{Li}^{2}$ \\ 'Chongqing Jianzhu College, Chongqing 400072, China \\ ${ }^{2}$ Department of Civil Engineering, Cleveland state university, Cleveland, $\mathrm{OH} 44115$, United States
}

Received 13 October 2017; Accepted 10 January 2018

\begin{abstract}
Owing to the frequent fluctuation of river water level and the stability control of bedding rock slope under high loading force of slope crest, the traditional slope stability control technology can hardly achieve the desired effect given its limitations. This study proposed a novel "anti-slide pile + supporting column" composite retaining structure to improve the stability of slope under this condition. The mechanical response characteristics of the composite retaining structure under the sliding force of the slope were studied through structural mechanics and finite element analyses. The difference in the internal force calculation results obtained through various methods was compared and analyzed, and the reliability of the calculation results was verified. Results show that the supporting column bears a significant axial pressure under the sliding force of the slope. Relative error is up to $85 \%$ between the internal force of the retaining structure obtained through displacement method without considering the axial deformation and the results obtained through other solving methods. The axial force of the supporting column is uniformly distributed along the column, and the bending moment and shear force of the column are relatively minimal. The axial force at the intersecting position between the anti-slide pile and the supporting column is the largest, and the maximum bending moment occurs at the part of the column near the embedded section. The shear forces at the contact position between the anti-slide pile and the supporting column and the part of the anti-slide pile near the embedded segment are relatively large. This study provides references for slope treatment engineering under similar conditions.
\end{abstract}

Keywords: Slope, Composite retaining structure, Finite element method, Structural analysis method, Mechanical response

\section{Introduction}

China has a vast territory with high mountains, great rivers, and complex terrain structures. Various housing, transportation, and water conservancy and hydropower construction projects have changed gradually with the rapid development of economy and society in recent years.

However, all types of engineering geological problems may occur in construction projects during the whole lifecycle of investigation, construction, and operation because the direct or indirect construction objects of engineering construction are complex rock and soil mass. Landslide is a common geological disaster in slope engineering. In accordance with statistical data[1], approximately 10,907 geological disasters occurred in China in 2014, including 8128 landslide disasters, which represent $74.5 \%$ of the total geological disasters. All types of landslides frequently occur despite efforts for preventing and controlling landslides. The typical landslides include Outang landslide in three Gorges Reservoir areas[2], reservoir bank landslide of Longjiang Hydropower Station in Yunnan[3], and West-East natural gas transmission pipeline landslide[4] All types of landslides occurred in other countries and regions around the world, such as the landslides in Vajont

*E-mail address: ii_qiao@163.com

ISSN: 1791-2377 @ 2018 Eastern Macedonia and Thrace Institute of Technology. All rights reserved. doi:10.25103/jestr.111.14 reservoir bank in Italy[5], Surte towns in Sweden[6], and a town in Mameyes, Puerto Rico[7]. Furthermore, landslide disasters have become a serious geological disaster that threatens human life and property safety. Therefore, a study on the stability control of landslides remains the focus of scholars in various countries. Domestic and foreign scholars have conducted numerous studies on slope stability evaluation[8-13] and instability mechanism and have achieved abundant study results.

However, various control factors can induce landslide given the special geological environment of slopes. Therefore, taking targeted control measures combined with geological conditions is the basis and premise of achieving favorable governance effects. At present, the traditional slope stability control technology, such as unloading, antislide pile, anchor-plate retaining, and reinforced soil[14-18], can hardly achieve the desired control effect in slope engineering with the abovementioned geological conditions given the limitations in their technical features.

Thus, this study proposes a novel "anti-slide pile + support column" composite retaining structure and explores the mechanical response characteristics of the slope under the effect of sliding thrust, thereby expecting to effectively improve the stability of the bedding rock slope under frequent river water level fluctuation and high loading force of slope crest. 


\section{State of the art}

In recent years, increasing traffic, water conservancy, and hydropower projects have been established in areas with complex geological conditions. However, because of different geological environments in all types of slope engineering projects, the conventional slope treatment measures can hardly adapt to the increasingly complex engineering geological conditions. Thus, a variety of novel slope treatment measures have been proposed in succession. For example, Dong et al[19] proposed a new frame heat anchor pipe slope retaining structure for slope instability caused by freezing and thawing cycles in permafrost regions. This structure regulates temperature balance between slope body and the atmosphere through "heat transfer refrigeration" and "retaining anchoring" systems and anchors the frozen and thawed active layer in the stable frozen layer to improve the stability of slope rock in frozen soil area. Jinbi[20] suggested a variable stiffness design method for cantilever double-row anti-slide pile, which adjusts the cross-section size or pile spacing in accordance with the difference in stress characteristics of the front and back piles and coordinates thrust distribution. This method slightly expands the application of cantilever double-row anti-slide pile in large or extra-large landslide treatment projects. Wang et al[21] proposed a novel anti-slide retaining structure with a bundled anti-slide pile and preliminarily studied the bending resistance of the anti-slide pile from the perspectives of theoretical analysis and experimental research because chopsticks with bonded ends are not likely to break in the longitudinal direction. Tiwari[22-23] analyzed the stability of slope under earthquake through numerical simulation. The slope anchorage support design scheme was adopted on the basis of the deformation and failure modes of slope observed in numerical simulation to guarantee that the slope deformation is within the allowable range. Danfeng[24-25] used finite element analysis software to analyze the coordination effect of the composite anti-slide system for the composite anchor cable-frame beam anti-slide pile anti-sliding system, which are frequently used in treatment projects of high and steep slopes with bedding sand mudstone subgrade. In accordance with the study results, the sharing value of the sliding force of the anti-slide pile is low when the sharing value of the sliding force of the prestressed anchor cable is high, and vice versa. The entire system has a high resistance to slope sliding force under the coordination of components in the anti-sliding system. Johnson[26] found that the high-cut slope with folded structure had a large deformation under earthquake, which can be effectively controlled through the support scheme of the anti-slide pile and retaining wall. Srilatha[27] analyzed the influence of seismic wave frequency on seismic response of reinforced earth slope through shaking table tests. The results show that the frequency significantly influences the seismic response of the slope, and the displacement response is significantly smaller in the reinforced earth slope than in the unreinforced slope. Bhowmik[28] utilized a composite test and finite element analysis software to analyze the mechanical behavior of hollow steel pile under horizontal dynamic load, and the numerical results agree well with the test. AlDefae[29-30] simulated the pressure effect of a moving vehicle on soil under the road through repetitive and discontinuous semi-sine curves and analyzed the slope stability under dynamic load of the vehicle on slope crest. Li[31-32] proposed a novel pile wall composite retaining structure, which has an ideal application effect by combining retaining walls between piles and pile foundation beam equilibrium-weight shoulder wall given the high and steep slopes with expansive soil. The targeted slope treatment measures combined with the site geological and local conditions are the basis for achieving favorable results, as previously mentioned. The abovementioned novel slope control measures are mainly concentrated in engineering projects of large-scale high and steep slopes with special lithologic characteristics in permafrost region under seismic action. The stability control of slopes with bedding rock under the frequent fluctuation of river water level and high loading force of slope crest is seldom studied, and minimal experience can be used for reference.

Therefore, this study proposes a novel "anti-slide pile + support column" composite retaining structure given the shortcomings of the existing studies. That is, the supporting column is embedded in the middle part of the cantilever section of the anti-slide pile. The support column, as a pivot of the anti-slide pile, can provide a large counterforce against the anti-slide pile and form a composite support system with the anti-slide pile to bear large slope thrust. In addition, the bottom end of the support column is embedded in deep bedrocks, which transfer most thrust directly to the bedrock at the foot of the slope.

The remainder of this study is organized as follows. Section 3 describes the method that is used to calculate the internal force of the composite retaining structure. Section 4 analyzes the mechanical response characteristics of the composite retaining structure under the sliding thrust of the slope and compares the differences between the internal force calculation results obtained by various analytical methods to further determine the designed internal force value of the retaining structure. Section 5 presents the conclusions.

\section{Methodology}

\subsection{Project profile}

A slope treatment project in Chongqing is considered the study object. The slope is a bedding rock slope that is approximately $46-52 \mathrm{~m}$ high and $110 \mathrm{~m}$ long, and the slope angle is approximately $40^{\circ}-60^{\circ}$. The slope rock is mainly the fourth member limestone of the Jialingjiang formation of the Triassic system and is relatively complete. An artificial stream was dug at the foot of the slope recently, and the rise and fall of the water level are frequent. The river bed is limestone with good integrity and high strength. Figure 1(a) illustrates the realistic picture of the slope. Two towers with frame structures and pile foundation are planned to be established at the crest of the slope. The results of the slope stability test show that the slope rock will bear a sliding thrust of $5000 \mathrm{kN} / \mathrm{m}$ after the towers are established, and the slope is in the unstable to basically stable state. In accordance with the engineering geological conditions of the slope, the conventional retaining structure, such as cantilever anti-slide pile, can hardly provide the required supporting force. The prestressed anchorage cable should not be arranged in the zone with the fluctuant water level. The upper anchorage cable should not interact with the constructed building foundation. These concepts significantly restrict the application of anchor cable. Therefore, a novel "anti-slide pile + support column" composite retaining structure is proposed in accordance with the characteristics of the project. The anti-slide pile bears the 
slope thrust. The supporting column is embedded in the middle part of the cantilever section of the anti-slide pile. The support column, as a pivot of the anti-slide pile, can provide a large counterforce against the anti-slide pile and form a composite support system with the anti-slide pile to bear large slope thrust. In addition, the bottom end of the support column is embedded in deep bedrocks, which transfer most thrust directly to the bedrock at the foot of the slope.

The section sizes of the anti-slide pile and supporting column, which is poured with $\mathrm{C} 30$ concrete, are determined to be $3.0 \mathrm{~m} \times 2.0 \mathrm{~m}$ and $2.0 \mathrm{~m} \times 2.0 \mathrm{~m}$, respectively, in accordance with the characteristics of slope rock mass and site construction conditions. The length of the embedded section is not less than $8.0 \mathrm{~m}$. The distance between the centers of the piles is $4.0 \mathrm{~m}$. The buried depth of support column foundation is $\geqslant 4.0 \mathrm{~m}$, and the embedded weathered rock formation is $\geqslant 2.5 \mathrm{~m}$. Figure 2 depicts the typical crosssection composite retaining structure.

The novel composite retaining structure differs significantly from the conventional retaining structure and is applied in practice minimally. Moreover, its mechanical response law under the lateral thrust of slope rock is unclear. To guarantee the stability of slope rock and composite retaining structure, the structural mechanics analysis and numerical calculation are jointly used to study the mechanical response law of the composite retaining structure under the lateral pressure of the slope rock.

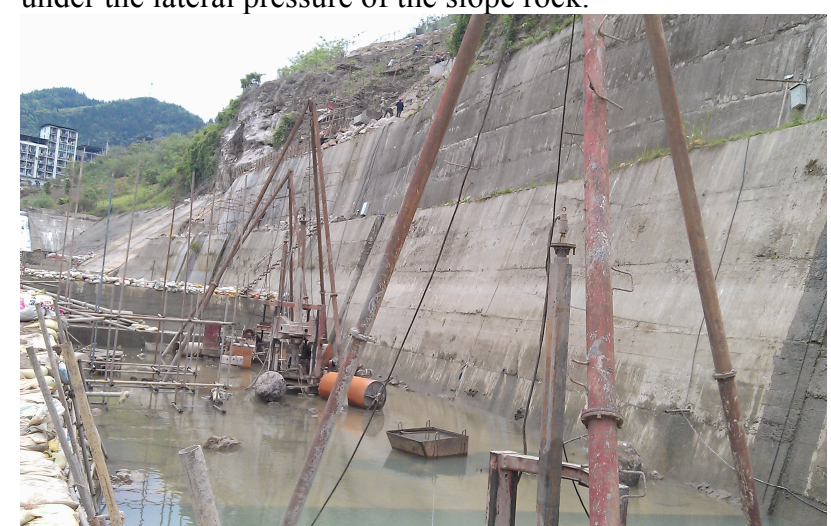

Fig. 1. Real map before slope treatment

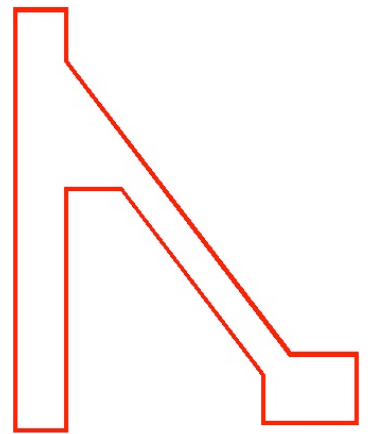

(a) Calculation profile of composite retaining structure
Fig. 3. Calculation profile and simplified calculation model of the composite retaining structure
The calculation model and the hypothetical conditions are consistent with the displacement solution method when the internal force distribution of composite retaining structure is solved through force-based method. However, this calculation only considers the axial deformation caused by the axial force, whereas the axial deformation of the pile caused by the vertical force of the sliding thrust is neglected.

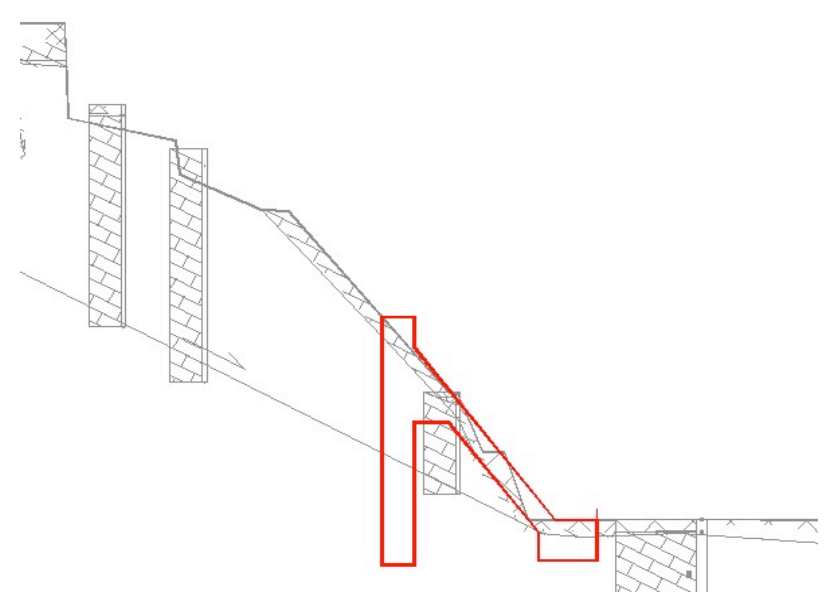

Fig. 2. Schematic of composite retaining structure

\subsection{Structural mechanics analysis}

The composite retaining structure is simplified as a bar system structure when the internal force distribution of the composite retaining structure is solved through displacement method. The length of each bar element is the length of the centerline of the composite structure. The joint of the antislide pile and the support is considered a rigid connection. The end of the support column is restrained by a hinge support.

The deformation caused by the axial force of the rod is neglected in the calculation. Only the angular displacement exists in the rigid node in the calculation model, but the line displacement does not occur. The non-embedded segment is $3.095 \mathrm{~m}$ long below the sliding surface of the anti-slide pile. The embedded segment constraint of the anti-slide pile is replaced by a fixed constraint. The sliding thrust is assumed to be a rectangular uniform distribution, and the included angle with the horizontal plane is $28^{\circ}$. The sliding thrust is exerted on the cantilever section above the sliding surface of the slide pile. Figure 3 demonstrates the calculation profile and simplified calculation model of the composite retaining structure.

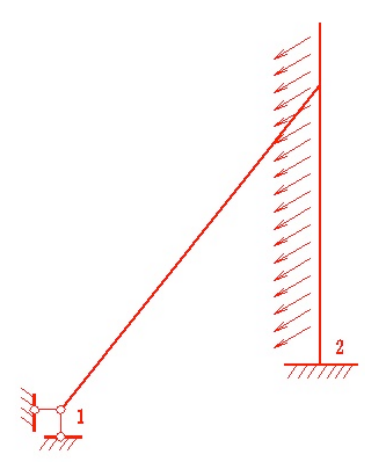

(b) Simplified calculation model
In addition, this study adopts an electric algorithm on the basis of computer programming to solve the internal force of the proposed composite retaining structure considering the complex structural mechanics solution of a statically indeterminate structure with axial deformation and large calculation amount. 


\subsection{Finite element method}

Finite element method is used to simulate the stress characteristics of the composite retaining structure by using the finite element software ANSYS. In the simulation, the composite retaining structure is simplified into a bar system. The joint of the anti-slide pile and supporting column is

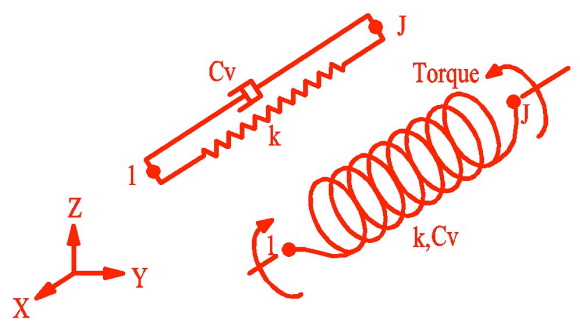

(a) Combin 14 spring element

Fig. 4. Schematic of ANSYS structural unit

Damping force and torque of the spring element can be obtained by using Formulas (1)-(3):

$$
\begin{aligned}
& F_{\mathrm{x}}=-C_{\mathrm{v}} \frac{d u_{\mathrm{x}}}{d t} \\
& T_{\theta}=-C_{\mathrm{v}} \frac{d \theta}{d t} \\
& C_{\mathrm{v}}=\left(C_{\mathrm{v}}\right)_{1}+v\left(C_{\mathrm{v}}\right)_{2}
\end{aligned}
$$

where $F_{\mathrm{x}}$ is the damping force; $T_{\theta}$ denotes the torque; $C_{\mathrm{v}}$ represents the damping coefficient, which is jointly determined by $\left(C_{\mathrm{v}}\right) 1$ and $\left(C_{\mathrm{v}}\right) 2$; and $v$ signifies the velocity. The axial and bending stresses of the beam element are obtained by Formulas (4) and (5), respectively.

$$
\begin{gathered}
\sigma_{\mathrm{i}}^{\mathrm{dir}}=\frac{F_{\mathrm{x}, \mathrm{j}}}{A} \\
\sigma_{\mathrm{i}}^{\mathrm{bnd}}=\frac{M_{\mathrm{i}} t}{2 I}
\end{gathered}
$$

where $\sigma{ }_{\mathrm{i}}^{\mathrm{dir}}$ is the axial stress, $A$ represents the cross-sectional area of the beam, $F_{\mathrm{x}, \mathrm{j}}$ denotes the axial force, $\sigma^{\text {bnd }}{ }_{\mathrm{i}}$ is the bending stress, $M_{\mathrm{i}}$ signifies the bending moment at $\mathrm{i}$ end of the beam, and $t$ symbolizes the stiffness of the beam along the Y direction. Figure 5 displays the finite element model for the composite retaining structure.

\section{Result Analysis and Discussion}

4.1 Internal force distribution of the composite retaining structure calculated through the displacement and force methods

Figure 6 illustrates the internal force of the composite support structure calculated through the displacement method. The maximum axial force of the support column is $20132.56 \mathrm{kN}$; this force is considered pressure. The maximum shear force is $16.57 \mathrm{kN}$, and the maximum bending moment is $458.25 \mathrm{kN} \cdot \mathrm{m}$. The maximum axial force of the anti-slide pile is $13512.69 \mathrm{kN}$ and is distributed at the junction of support and pile. This force is a tensile force, considered the rigid connection, and the support end is restrained by the hinge support. Spring element Combin 14 is selected to simulate the embedding effect of the stratum embedded with the anti-slide pile. The anti-slide pile and support column are simulated through the plane beam element Beam3. Figure 4 exhibits the schematic of the spring and beam elements.

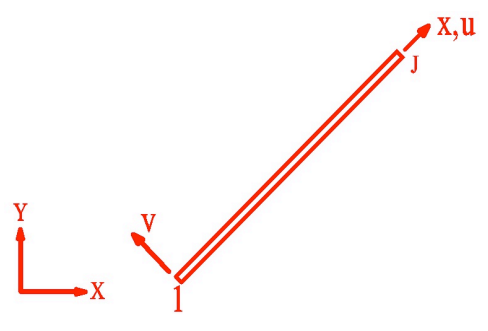

(b) Beam3 beam element

namely, a pull-up force on the pile. The axial force near the embedded section is $4985.26 \mathrm{kN}$ and is a tensile force. The maximum shear force is $8768.93 \mathrm{kN}$ and is distributed at the junction between the support and the pile. Moreover, the shear force near the embedded section is $7156.83 \mathrm{kN}$. The maximum bending moment is $22568.76 \mathrm{kN} \cdot \mathrm{m}$ and is distributed near the embedded section. The inner side of the pile is pulled.

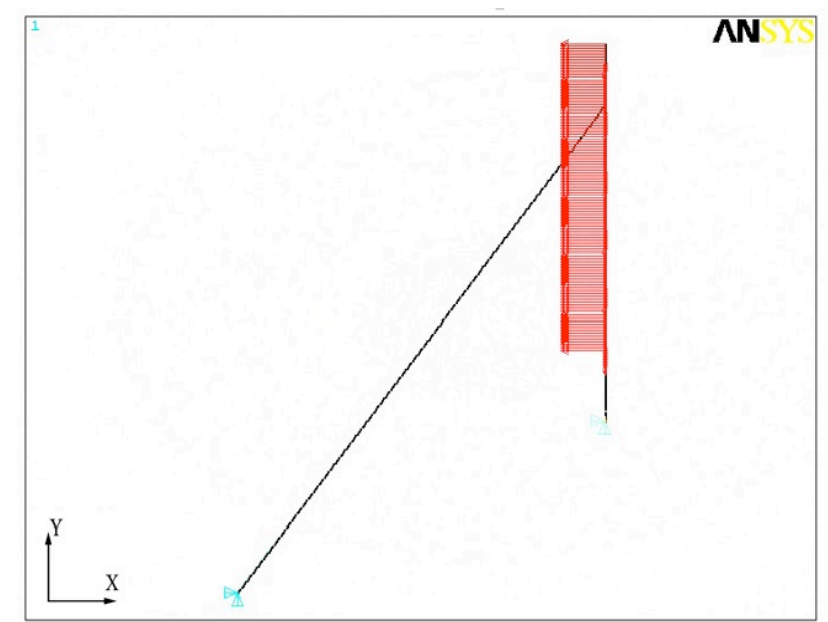

Fig. 5. Finite element calculation model of the composite retaining structure

Figure 7 depicts the internal force calculation result of the composite retaining structure based on the force method. The maximum axial force of the support column is 17187.34 $\mathrm{kN}$ and is considered the pressure. The maximum shear force is $9.35 \mathrm{kN}$, and the maximum bending moment is $253.31 \mathrm{kN} \cdot \mathrm{m}$. The maximum axial force of the anti-slide pile is $11633.72 \mathrm{kN}$ and is distributed at the junction of support and pile. This force is a tensile force, namely, a pull-up force on the pile. The maximum shear force is $9427.23 \mathrm{kN}$ and is distributed near the embedded section. Moreover, the shear force at the junction of the support and the pile is 6426.99 $\mathrm{kN}$. The maximum bending moment is $51014.25 \mathrm{kN} \cdot \mathrm{m}$ and is distributed near the embedded section. The inner side of the pile is pulled. 


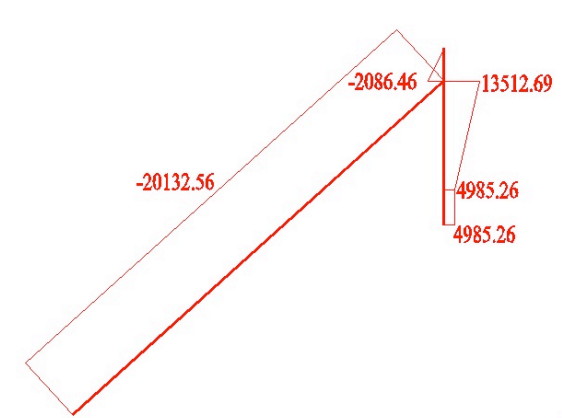

(a) Axial force $/ \mathrm{kN}$

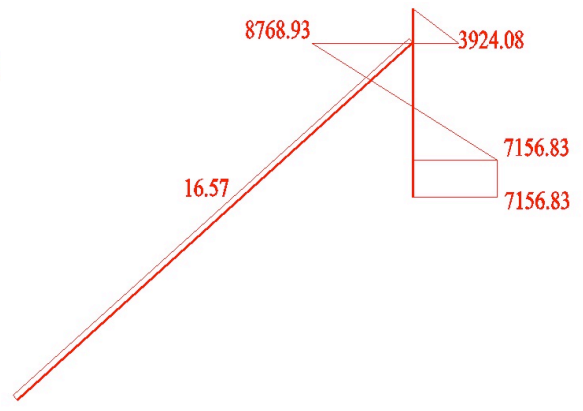

(b) Shear force/kN

Fig. 6. Internal force distribution of the composite retaining structure based on the displacement method

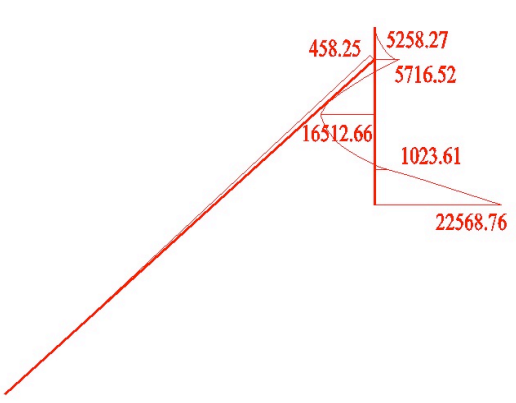

(c) Bending moment $/ \mathrm{kN} \cdot \mathrm{m}$

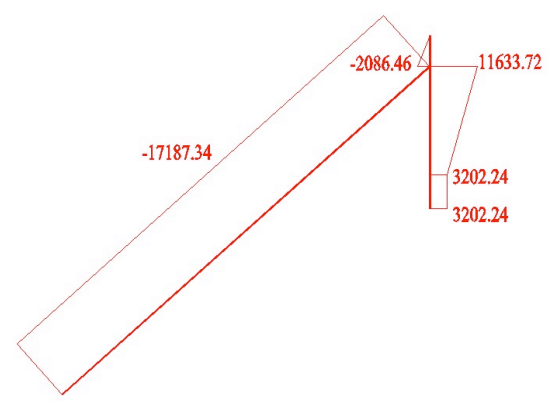

(a) Axial force/kN

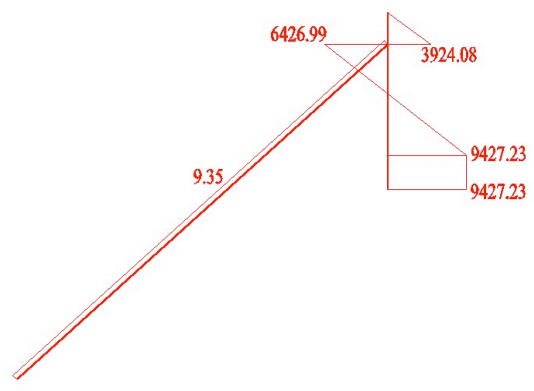

(b) Shear force/kN

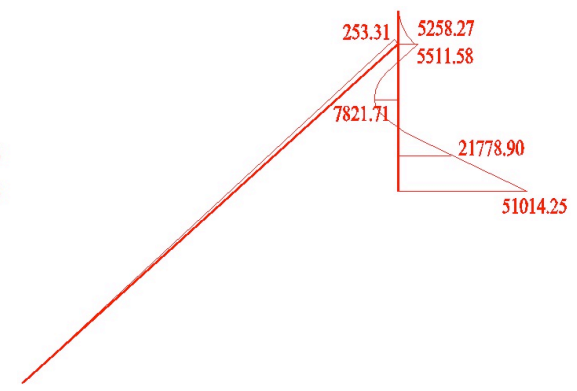

(c) Bending moment $/ \mathrm{kN} \cdot \mathrm{m}$

Fig. 7. Internal force distribution of the composite retaining structure on the basis of force method

\subsection{Internal force distribution of the composite retaining structure based on the electric algorithm}

This study adopts an electric algorithm on the basis of computer programming to solve the internal force of the proposed composite retaining structure considering the complex structural mechanics solution of a statically indeterminate structure with axial deformation and large calculation amount. Figure 8 demonstrates the calculation result.

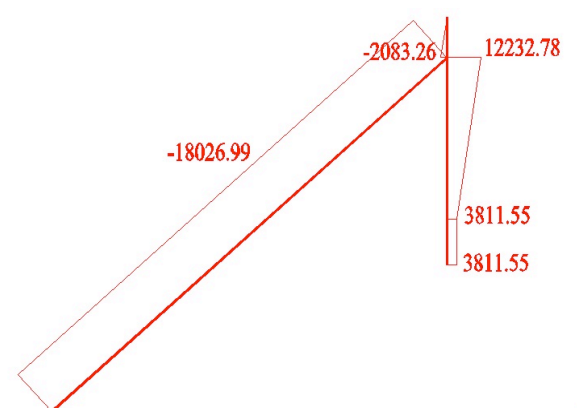

(a) Axial force/ $\mathrm{kN}$

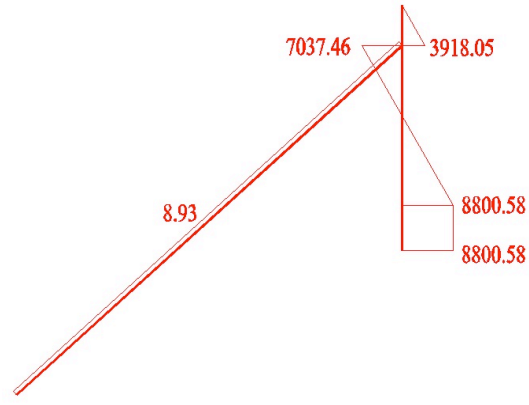

(b) Shear force/kN

Fig. 8. Internal force distribution of the composite retaining structure based on the electric algorithm

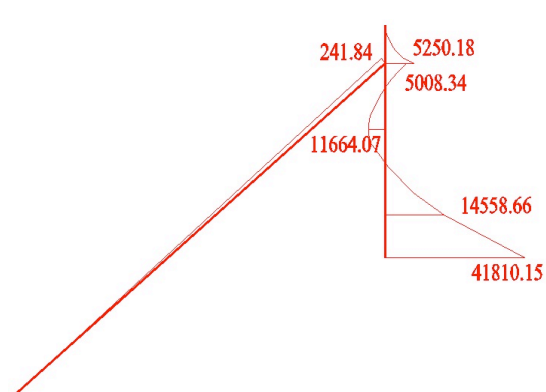

(c) Bending moment $/ \mathrm{kN} \cdot \mathrm{m}$
In Figure 8, the maximum axial force of the support column is $18026.988 \mathrm{kN}$ and is considered the pressure. The maximum shear force is $8.930 \mathrm{kN}$, and the maximum bending moment is $241.845 \mathrm{kN} \cdot \mathrm{m}$. The maximum axial force of the anti-slide pile is $12232.784 \mathrm{kN}$ and is distributed at the junction of support and pile. This force is a tensile force, namely, a pull-up force on the pile. The maximum shear force is $8800.580 \mathrm{kN}$ and is distributed near the embedded section. Moreover, the shear force at the junction of the support and the pile is relatively large at $7037.462 \mathrm{kN}$. The maximum bending moment is $41810.150 \mathrm{kN} \cdot \mathrm{m}$ and is distributed near the embedded section. The inner side of the pile is pulled.

\subsection{Finite element calculation results based on rod element}

Figure 9 exhibits the finite element calculation results based on the force method. The maximum axial force of the support column is $17900 \mathrm{kN}$ and is considered the pressure. The shear force and bending moment are relatively minimal. The maximum axial force of the anti-slide pile is $12100 \mathrm{kN}$ and is distributed at the junction of support and pile. This force is a tensile force, namely, a pull-up force on the pile. The maximum shear force is $8880 \mathrm{kN}$ and is distributed near the embedded section. Moreover, the shear force at the junction of the support and the pile is relatively large at 6840 $\mathrm{kN}$. The maximum bending moment is $42700 \mathrm{kN} \cdot \mathrm{m}$ and is distributed near the embedded section. The inner side of the pile is pulled. 


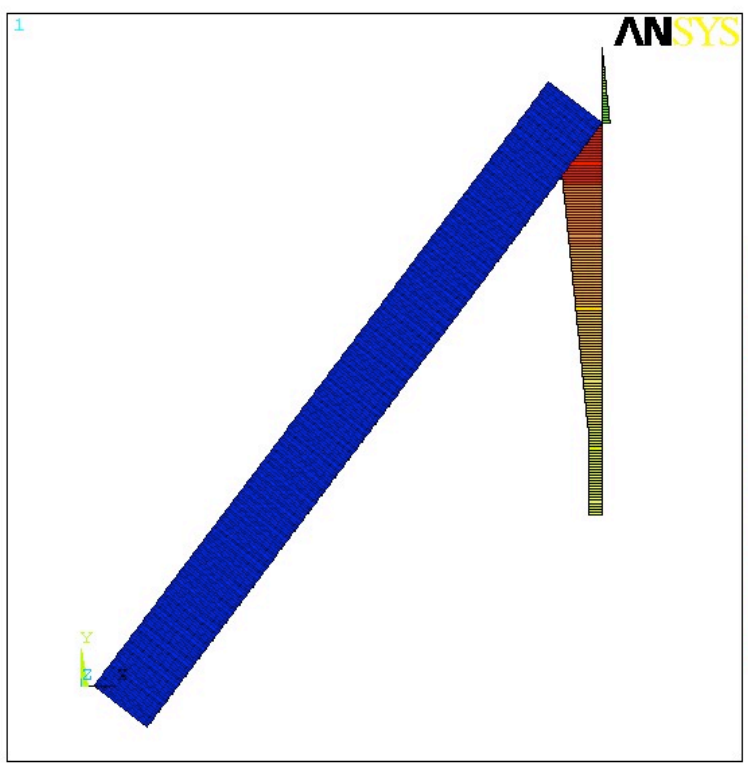

LINE STRESS

STEP $=1$

SUB $=6$

TIME $=1$

NI

ELEM $=168$

MAX $=.121 \mathrm{E}+08$

ELEM $=140$

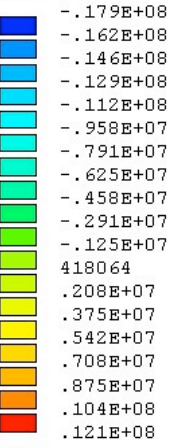

(a) Axial force $/ \mathrm{kN}$

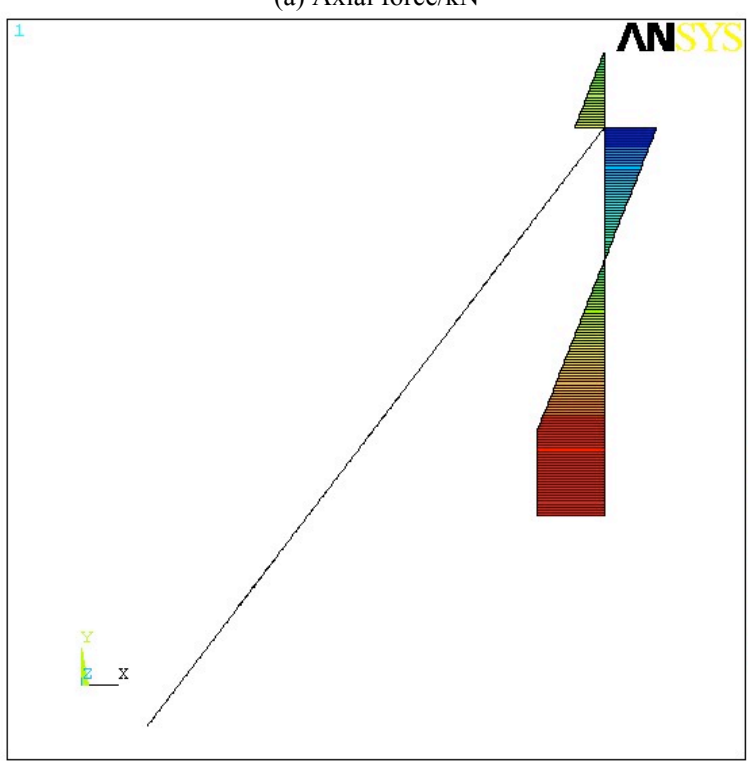

LINE STRESS

STEP $=1$

SUB $=$

TIME $=1$

QI $\quad$ QJ

ELEM $=140$

MAX $=.888 \mathrm{E}+07$

ELEM=1

$-.684 \mathrm{E}+07$
$-.597 \mathrm{E}+07$

$-.597 \mathrm{E}+07$

$-.509 \mathrm{E}+07$

$-.422 \mathrm{E}+07$

$-.335 \mathrm{E}+07$

$-.247 \mathrm{E}+07$

$-.160 \mathrm{E}+07$

$-726133$

$102 \mathrm{E}+07$

$102 \mathrm{E}+07$
$189 \mathrm{E}+07$

$.277 \mathrm{E}+07$

$364 \mathrm{E}+07$

$451 \mathrm{E}+07$

$.539 \mathrm{E}+07$

. $626 \mathrm{E}+07$

$.714 \mathrm{E}+07$
$-801 \mathrm{E}+07$

$801 \mathrm{E}+07$

(b) Shear force $/ \mathrm{kN}$

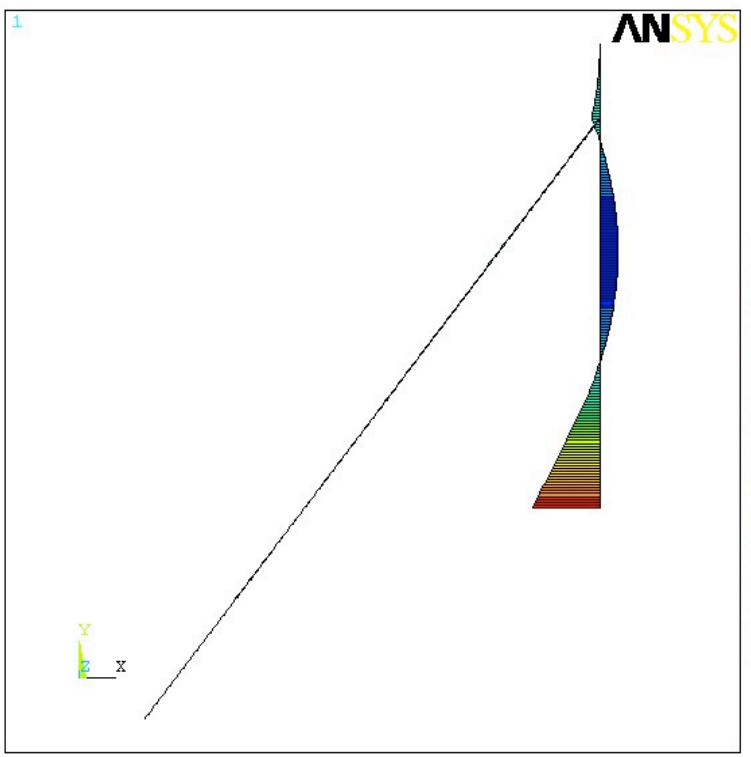

INE STRES

STEP $=1$

SUB $=6$

TIME $=1$

MI MJ

IIN $=-.115 \mathrm{E}+08$

ELEM $=92$

LAX $=.427 \mathrm{E}+08$

ELEM $=1$

$-.115 \mathrm{E}+08$
$-.850 \mathrm{E}+07$
$-.549 \mathrm{E}+07$

$-.247 \mathrm{E}+07$

539533

$.958 \mathrm{E}+07$

$186 \mathrm{E}+08$

$216 \mathrm{E}+08$

$277 \mathrm{E}+08$

$337 \mathrm{E}+08$

$397 \mathrm{E}+08$

$.427 \mathrm{E}+08$

(c) Bending moment $/ \mathrm{kN} \cdot \mathrm{m}$

Fig. 9. Internal force distribution nephogram of the composite retaining structure 
4.4 Comparison and analysis of the internal force calculation results

The peak values of internal forces calculated through the different calculation methods are extracted to compare the difference in the internal force distributions of the composite retaining structure; the results are summarized in Table 1.

Table 1 summarizes a significant difference in the internal force values of the composite retaining structure that is calculated through the displacement method without considering the axial deformation and the force method considering the axial deformation. The internal force value that is calculated through the force method is near the values calculated through the electric and finite element methods. This result indicates that the axial deformation caused by the axial force cannot be ignored. In accordance with the data analysis results, the relative error between the internal force of the retaining structure calculated through the displacement method and the internal force (mean value) obtained through the other three methods is up to $85 \%$. A large error is observed in the internal force value of the retaining structure that is calculated through the displacement method without considering the axial deformation. In addition, the data in Table 1 denote that the supporting column bears the axial pressure of up to 17607.2 $\mathrm{kN}$ (the mean of the results obtained by the force, electric, and finite element methods). Therefore, the axial deformation of the composite retaining structure cannot be ignored by regarding it as a general frame structure. The result calculated through the force method agrees well with that obtained through the electrical method, except for the difference in several values, considering the deformation caused by the axial force. This result is mainly caused by the axial deformation of the pile that resulted from the vertical force, which is excluded from the sliding thrust in the calculation through the force method. In the numerical simulation, the shear force and bending moment of the support column are minimal, and the peak value of the axial force is near the result of structural mechanics calculation. The distribution characteristics and values of the internal force of the anti-slide pile are similar to the structural mechanics calculation results.

Table 1. Comparison of the internal force calculation results of the composite retaining structures

\begin{tabular}{|c|c|c|c|c|c|c|}
\hline & \multicolumn{3}{|c|}{ Support column } & \multicolumn{3}{|c|}{ Anti-slide pile } \\
\hline & Axial force/kN & Shear force/kN & $\begin{array}{c}\text { Bending } \\
\text { moment/kN·m }\end{array}$ & Axial force/kN & Shear force/kN & $\begin{array}{c}\text { Bending } \\
\text { moment } / \mathbf{k N} \cdot \mathbf{m}\end{array}$ \\
\hline $\begin{array}{l}\text { Displacement } \\
\text { method }\end{array}$ & 20132.56 & 16.57 & 458.25 & 13512.69 & 8768.93 & 22568.76 \\
\hline Force method & 17187.34 & 9.35 & 253.31 & 11633.72 & 6426.99 & 51014.25 \\
\hline Electric method & 18026.99 & 8.93 & 241.85 & 12232.78 & 7037.49 & 41810.15 \\
\hline $\begin{array}{c}\text { Finite element } \\
\text { method }\end{array}$ & 17900.00 & small & small & 12100.00 & 8880.00 & 42700.00 \\
\hline
\end{tabular}

The mechanical response characteristics of the composite retaining structure under the effect of sliding thrust can be summarized as follows: the axial force of the support column uniformly distributes along the column. The column is under pressure, and the bending moment and shear force are relatively minimal. The axial force of the anti-slide pile is linearly distributed along the pile, and the peak value of the axial force is located at the junction with the support column. The bending moment is nonlinearly distributed along the pile. The maximum bending moment occurs at the part near the embedded segment. The shear force is linearly distributed along the pile, whereas the shear forces at the junction between the anti-slide pile and support column and the part of the anti-slide pile near the embedded segment are large.
The internal force distribution characteristics of the composite support structure obtained by the force, electric, and finite element methods are basically the same in accordance with the calculation results through the structural mechanics and finite element analysis methods, except for the displacement method. Moreover, the internal force values are similar. This result proves the reasonability of the method used in this study to calculate the internal force of the composite retaining structure and the reliability of the calculated results.

In accordance with the calculation results of the abovementioned methods given certain safety factors, the designed internal force distribution of the composite retaining structure is determined as exhibited in Figure 10.

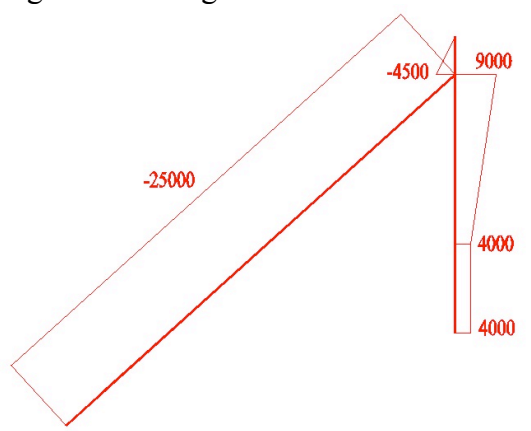

(a) Axial force $/ \mathrm{kN}$

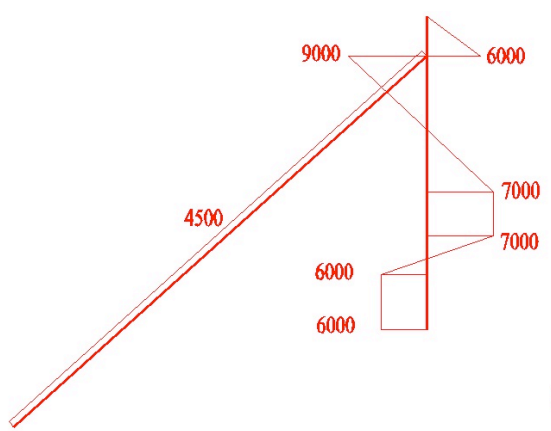

(b) Shear force/kN

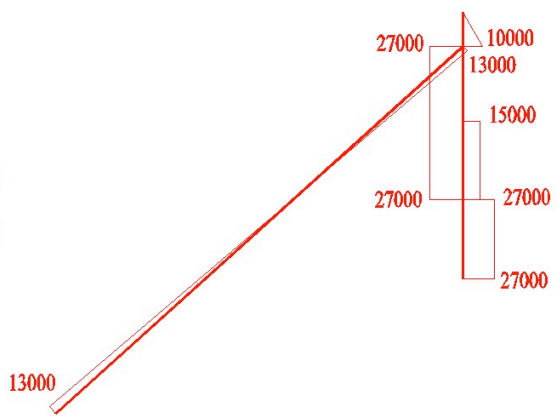

(c) Bending moment $/ \mathrm{kN} \cdot \mathrm{m}$

Fig. 10. Design internal force of the composite retaining structure

\section{Conclusions}

This study proposed a novel "anti-slide pile + supporting column" composite retaining structure to improve the stability of slope under this geological condition considering the frequent fluctuation of river water level and the stability control of bedding rock slope under high loading force of slope crest. The internal force values at different parts of the 
composite retaining structure under the sliding force of the slope were calculated through structural mechanics and finite element analyses. The mechanical response characteristics of the composite retaining structure were analyzed. Moreover, the design internal force of the retaining structure is determined. Finally, the following conclusions could be drawn:

(1)The relative error between the internal force of the retaining structure that is calculated through the displacement method without considering the axial deformation and the internal force (mean value) obtained through the other three methods is up to $85 \%$. Therefore, the axial deformation caused by the axial force in the composite retaining structure cannot be ignored. Moreover, the supporting column under the action of sliding force bears the axial pressure of up to $17607.2 \mathrm{kN}$. The axial deformation of the composite retaining structure should not be ignored by regarding it as a general frame structure.

(2)The mechanical response characteristics of the composite retaining structure can be summarized as follows: the axial stress of the support column is uniformly distributed along the column, and the column is in the compression state. The bending moment and shear force of the support column are relatively minimal. The peak value of the axial force at the anti-slide pile is at the junction with the support column. The maximum bending moment is at the part near the embedded section. The shear forces at the junction of the anti-slide pile and the supporting column and at the part near the embedded section are large.
(3)Based on the force, electric, and finite element analysis methods, the internal force distribution characteristics of the composite retaining structure are obtained. The results through comparison and analysis obtained by different calculation methods are similar, thereby verifying the reliability of the calculation results. Thus, the design internal forces at various parts of the composite retaining structure are determined.

This study obtained the mechanical response characteristics of a novel "anti-slide pile + support column" composite retaining structure under the effect of slope sliding force combined with multiple methods. The composite retaining structure can provide a reference for the slope treatment engineering under similar conditions. However, future study will combine with field monitoring data given the lack of field measurement data to further investigate the load-bearing mechanism of the novel composite retaining structure.

\section{Acknowledgements}

This study was supported by the Science and Technology Research Project of Chongqing Municipal Education Commission (Study of Mechanical Characteristics of the "Anti-slide Pile + Oblique Bracing" Composite Supporting Structure [KJ1604101]) and the Youth Research Fund Project of Chongqing Jianzhu College (Study of Mechanical Characteristics of h-shaped Anti-slide Pile [QN2015004]).

\section{References}

1. Zhang, J., Yin, K. L., Wang, J. J.,"Evaluation of landslide susceptibility for Wanzhou district of Three Gorges Reservoir". Chinese Journal of Rock Mechanics and Engineering, 35(2), 2016, pp. 284-296.

2. Dai, Z. W., Yin, Y. P., Wei, Y. J., "Deformation and failure mechanism of Outang landslide in three gorges reservoir area". Journal of Engineering Geology, 24(1), 2016, pp. 44-55.

3. Li, Z., He, Y. J., Sheng, J. B., "Landslide model for slope of reservoir bank under combined effects of rainfall and reservoir water level". Chinese Journal of Geotechnical Engineering, 39(3), 2016, pp. 452-459.

4. Wang, J. E., Xiang, W., Zuo, X., "Situation and prevention of loess water erosion problem along the west-to-eastgas pipeline in China". Journal of Earth Science, 21(6), 2010, pp. 968-973.

5. Paronuzzi, P., Bolla, A., "The prehistoric Vajont rockslide: An updated geological model”. Geomorphology, (169/170), 2012, pp.165-191.

6. Lindberg, F., Olvmoa, M., Bergdahl, K., "Mapping areas of potential slope failures in cohesive soils using a shadow-casting algorithm-A case study from SW Sweden". Computers and Geotechnics, 38(6), 2011, pp. 791-799.

7. Lepore, C., Kamal, S. A., Shanahan, P., "Rainfall-induced landslide susceptibility zonation of Puerto Rico". Environmental Earth Sciences, 66(6), 2011, pp. 1667-1681.

8. Zong, H. L., Yang, H., Dalia, K., "Evaluation of TRIGRS (transient rainfall infiltration and grid-based regional slope-stability analysis)'s predictive skill for hurricane-triggered landslides: a case study in Macon County, North Carolina". Nat Hazards, 58(2011), 2011, pp. 325-339.

9. Ji, J., Liao, H. J., Low, B. K., "Modeling 2-D spatial variation in slope reliability analysis using interpolated autocorrelations". Computers and Geotechnics, (40), 2012, pp. 135-146.

10. Song, Y. S., Hong, W. P., Woo, K. S., "Behavior and analysis of stabilizing piles installed in a cut slope during heavy rainfall". Engineering Geology, 129-130(2012), 2012, pp. 56-67.

11. Salmi, E. F., Hosseinzadeh, S., "Slope stability assessment using both empirical and numerical methods: a case study". Bulletin of Engineering Geology and the Environment, 74(1), 2015, pp. 13-25.

12. Spreafico, M. C., Francioni, M., Cervi, F., "Back analysis of the 2014 San Leo landslide using combined terrestrial laser scanning and 3D distinct element modeling"Rock Mechanics \& Rock Engineering, 49(6), 2015, pp. 1-17.
13. Salvoni, M., Dight, P. M., "Rock damage assessment in a large unstable slope from microseismic monitoring-MMG century mine (Queensland, Australia) case study". Engineering Geology, 210, 2016, pp. 45-56.

14. Zhao, B., Wang, Y. S., Wang, Y., "Retaining mechanism and structural characteristics of $\mathrm{h}$ type anti-slide pile (hTP pile) and experience with its engineering application". Engineering Geology, 222, 2017, pp. 29-37.

15. Hong, M. T., Wei, Z. C., Dian, S. Y., "Numerical analysis on the interaction of shotcrete liner with rock for yielding supports". Tunneling and Underground Space Technology, 54, 2016, pp. 2028.

16. Li, N., Zhang, P., Yu, C., "Research on method of numerical simulation of prestressed anchor cable in slope". Chinese Journal of Rock Mechanics and Engineering, 26 (2), 2007, pp. 254-260.

17. Gao, Y. F., Ye, M., Zhang, F., "Three-dimensional analysis of slopes reinforced with piles". Journal of Central South University, 22, 2015, pp. 2322-2327.

18. Park, J. B., Kim, D., Yang, S. B., "Pullout Characteristics of geosynthetics reinforced earth using multilayer spreading pullout test". Advances in Materials Science and Engineering, 2017, 2017, pp. 111.

19. Dong, X. G., Dong, J. H., He, T. H., "Invention and simplified design method of slope supporting structure of frame and heat anchor pipe in permafrost regions". Journal of the China Railway Society, 39(7), 2017, pp. 142-150.

20. Ye, J. B., Xie, Q., "Model test study on the behavior of double-row antisliding piles". Electronic Journal of Geotechnical Engineering, 18, 2013, pp. 5149-5160.

21. Wang, K., Zheng, Y. R., Wang, Q. H., "Experimental study on reinforced-concrete model of the trussed slide-resistant pile". Chinese Journal of Underground Space and Engineering, 4(6), 2008, pp. 1027-1032.

22. Tiwari, G., Latha, G. M., "Design of rock slope reinforcement: An Himalayan case study". Rock Mechanics \& Rock Engineering, 50(7), 2016, pp. 1-23.

23. Tiwari, G., Gali, M. L., "Reliability analysis of a himalayan rock slope considering uncertainty in post peak strength parameters". Rock Mechanics \& Rock Engineering, (284), 2017, pp. 183-192. 
24. Li, D. F., Wang, L. J., "Synergism analysis of bedding slope with piles and anchor cable support under sine-wave vehicle load". Advances in Materials Science and Engineering, 2016(3), 2016, pp. $1-8$.

25. Li, D. F., Wang, L. J., Ge, B. J., "The determination of the limit Skew angle of rock cutting slope along strata slip". International Journal of Earth Sciences and Engineering, 8(6), 2015, pp. 27192724.

26. Johnson, P. L., Shires, P, O., Sneddon, T. P., "Geologic and geotechnical factors controlling incipient slope instability at a gravel quarry". Environmental \& Engineering Geoscience, 22(2), 2016, pp. 141-155.

27. Srilatha, N., Latha, G. M., Puttappa, C. G., "Effect of frequency on seismic response of reinforced soil slopes in shaking table tests". Geotextiles and Geomembranes, 36, 2013, pp. 27-32.
28. Bhowmik, D., Baidya, D. K., Dasgupta, S. P., "A numerical and experimental study of hollow steel pile in layered soil subjected to lateral dynamic loading". Soil Dynamics and Earthquake Engineering, 53, 2013, pp. 119-129.

29. Al-Defae, A. H., Caucis, K., Knappett, J. A., "After shocks and whole-life seismic preformance of granular slope". Geotechnique, 63(14), 2013, pp. 1230-1244.

30. Al-Defae, A. H., Knappett, J. A., "Newmark sliding block model for pile-reinforced slopes under earthquake loading". Soil Dynamics and Earthquake Engineering, 75, 2015, pp. 265-278.

31. Gao, L., Li, H. G., Nie, W. F., "Research on application of new pilewall composite structure in high and steep slope support". Subgrade Engineering, (3), 2017, pp. 184-187.

32. Gao, L., "Analysis of new retaining structure and method of railway cutting slope of expansive soil". High Speed Railway Technology, 8(2), 2017, pp. 74-77. 